\title{
Aplicabilidade do Código de Defesa do Consumidor às Operações Bancárias
}

\section{Applicability of the Consumer's Code of Defense to Bank Operations}

\author{
Juliane Caravieri Martins Gamba1
}

\begin{abstract}
Resumo
O Código de Defesa do Consumidor trouxe significativa mudança nas relações jurídicas de consumo, pois é um código geral do consumo com normas cogentes e de ordem pública. Há discussões doutrinárias sobre a aplicabilidade do Código de Defesa do Consumidor às operações bancárias, havendo segmentos que a negam. O objetivo do trabalho é demonstrar que o Código de Defesa do Consumidor tutela todas as operações bancárias, inclusive os contratos de crédito que são espécies do gênero contratos bancários, pois são relações jurídicas de consumo, estando presentes seus elementos: fornecedores, consumidores, produtos ou serviços. O crédito possui papel fundamental na atual sociedade de consumo, pois é o fomentador das atividades empresariais e pessoais. Os contratos de crédito bancário são do tipo adesão porque possuem cláusulas e condições gerais preestabelecidas unilateralmente pelos bancos (predisponente ou pólo ativo da relação contratual), em detrimento do mutuário-consumidor (aderente ou pólo passivo) sem que este possa discutir ou modificar substancialmente o conteúdo contratual. Portanto, defende-se a ampla incidência do Código de Defesa do Consumidor às operações bancárias, em especial aos contratos de crédito, protegendo o consumidor (pessoa física ou jurídica) exposto às práticas abusivas cometidas pelos bancos nas relações jurídicas de consumo da sociedade moderna. Palavras-chave: Direito do consumidor, operações bancárias, crédito.
\end{abstract}

\begin{abstract}
The Consumer's Code of Defense has brought significant changes to the juridical relation of consumption, because it is a general code of consumption with coercive and of public order norms. There are doctrinaire discussions on the applicability of the Consumer's Code of Defense to bank operations, but there are segments that deny it. The purpose of this work is to demonstrate that the Consumer's Code of Defense tutors all bank operations, including the credit contracts which are a kind of the genre bank contracts, for they are juridical relations of consumption, with the following elements: suppliers, consumers, products or services. The credit exerts an important role on the current society of consumption because it is the supporter of the entrepreneurial and personal activities. The contracts of bank credit are adhesion-like because they have clauses and general conditions established unilaterally and previously by the banks (authoritative agent or active pole of the contractual relationship) to the detriment of the borrowerconsumer (adherent or passive pole) who has no choice to discuss or modify substantially the contract content. Thus, the wide occurrence of the Consumer's Code of Defense to bank operations is supported especially to the credit contracts, protecting the consumer (individual or legal entity) exposed to abusive practices performed by the banks in juridical relations of consumption of the modern society.

Key words: Consumer's right, bank operations, credit.
\end{abstract}

\footnotetext{
${ }^{1}$ Bacharel em Ciências Econômicas pela Universidade Estadual Paulista (UNESP); Especialista em Economia Empresarial pela Universidade Estadual de Londrina (UEL); Bacharel em Direito pela Universidade Estadual de Londrina (UEL) e advogada, autora da pesquisa "Impactos do Código de Defesa do Consumidor (CDC) nos Contratos de Leasing: Aspectos Doutrinários e Jurisprudenciais" realizada junto ao Departamento de Direito Privado da Universidade Estadual de Londrina (UEL). Av. Vereador Dante Jordão Stoppa, 404, B1.7 Apt ${ }^{\circ}$ 13-César de Souza-08820-390-Mogi das Cruzes-SP . e-mail- jcaravierigamba@uol.com.br
} 


\section{Introdução}

O tema do presente artigo é relevante e atual, pois apesar do Código de Defesa do Consumidor (CDC) possuir mais de dez anos de vigência, ainda há resistência em diversos setores da sociedade, notadamente por parte dos Bancos, e alguns operadores do direito quanto à sua aplicabilidade nas relações jurídicas bancárias.

A Confederação Nacional do Sistema Financeiro que congrega a Federação Nacional dos Bancos, a Federação Nacional das Empresas Distribuidoras de Títulos e Valores Mobiliários, a Federação Interestadual das Instituiçõos de Crédito, Financiamento e Investimentos e a Federação Nacional das Empresas de Seguros Privados e Capitalização ingressou no Supremo Tribunal Federal com uma Ação Direta de Inconstitucionalidade (ADIN 2591), visando, primordialmente, que sejam desconsiderados os serviços bancários como relações de consumo.

Mostra-se absurda essa posição porque pretende sufocar o Direito do Consumidor e limitar sua aplicabilidade, não podendo prosperar no mundo jurídico, pois significaria uma volta ao passado e um retrocesso nas garantias concedidas aos economicamente mais fracos no mercado de consumo.

Nesse sentido, o estudo proposto Aplicabilidade do Código de Defesa do Consumidor às Operações Bancárias estão envolvidas questões de diversas ordens:

a) a análise do Direito do Consumidor como novo ramo jurídico;

b) a nova sistemática imposta pelo CDC às relações jurídicas de consumo, evitando abusividades e desequilíbrios, sendo instrumento de pacificação de conflitos;

c) a definição do âmbito, do significado e da viabilidade da aplicação do CDC às operações bancárias; d) a natureza jurídica de contratos de adesão dos instrumentos firmados entre o banco (predisponente) e o usuário (aderente), ensejando a aplicação do CDC para o equilíbrio dessas relações jurídicas.

O Código de Defesa do Consumidor, Lei 8.078, de 11 de novembro de 1990, alterou significamente a tutela das relações jurídicas de consumo através de princípios e normas de ordem pública e de caráter cogente, prevalecendo nessas relações os interesses sociais, o império da lei sobre a autonomia da vontade individual e a proteção dos economicamente mais fracos.

O objetivo do artigo é demonstrar que o Código de Defesa do Consumidor tutela todas as operações bancárias, pois são relações jurídicas de consumo, estando presentes seus elementos: fornecedores, consumidores, produtos ou serviços.

Desse modo, a pesquisa visa abordar os diferentes aspectos que norteiam a aplicação do Código de Defesa do Consumidor nas atividades bancárias. Entretanto, não se objetiva exaurir os questionamentos em relação a essa temática, mas, sobretudo, contribuir para o enriquecimento das discussões sobre a eficácia do CDC como disciplinador das relações jurídicas de consumo na sociedade atual.

\section{O Direito do Consumidor}

Surgimento do Código de Defesa do Consumidor: aspectos históricos

No séc. XIX, o mundo sofreu significativas alterações econômico-tecnológicas e o capitalismo impôs novas formas de produção. As relações sociais se caracterizavam pelo individualismo refletindo os ideais liberais da época e a não intervenção do Estado em todas as esferas da sociedade.

No Brasil já se consolidavam os institutos jurídicos da liberdade e da propriedade oriundos desse ambiente mundial, através da publicação do Código 
Civil de 1916 que privilegiava a autonomia da vontade nas relações jurídicas e a não-intervenção estatal. Essa codificação sofreu nítida influência de uma concepção individualista e liberal do Direito presente na Declaração dos Direitos do Homem de 1789 e do Código Civil Francês de 1804.

A princípio, esse ordenamento jurídico atendeu aos anseios da época. Entretanto, com o desenvolvimento econômico, social, político, etc., impôs-se à alteração desse modelo jurídico, pois as normas até então existentes, como disciplinadoras de conduta, não mais exerciam uma função pacificadora dos conflitos sociais.

O Direito, como possuidor dessa força pacificadora, deve entrar em consonância com as reais necessidades de um povo, acompanhando o desenvolvimento dos costumes e ideais que delineiam o perfil de uma nação.

O modelo capitalista mundial permitiu a formação de monopólios e oligopólios empresariais que, associados às novas tecnologias, revolucionaram o processo produtivo. Desenvolveu-se a produção em massa com reduzidos custos, buscando um mercado consumidor capaz de absorver os produtos e gerar lucros cada vez maiores.

Está-se diante da sociedade moderna altamente capitalista e movida por um consumismo exacerbado, sendo o crédito e o marketing os instrumentos facilitadores desse processo. As pessoas perderam sua individualidade, pois são vistas apenas como potenciais consumidores que, para estarem satisfeitos, têm que consumir mais e mais.

Criou-se um sistema poderoso de marketing, altamente persuasivo e motivador que induz os consumidores a comprar pelo prazer de comprar e não simplesmente por atender às suas necessidades vitais básicas. Aliado a esse marketing está o crédito, sendo estimulado pelas instituições financeiras e bancárias como a solução para todos os desejos consumistas. Porém, mascaram-se os juros e as condições abusivas em que esse crédito é concedido, iludindo os consumidores.
O destinatário de todo esse sistema mercadológico deveria, logicamente, figurar como o maior beneficiário das transformações econômicas ocorridas, afinal é para o consumidor que se destina toda a produção, é pensando nele que se aprimoram os produtos e serviços; todo o lucro do fornecedor provém dos consumidores. No entanto, ao invés da situação beneficiá-lo, esse processo produtivo, em busca sempre da ampliação de lucros, colocou-o em situação de extrema fragilidade, ou melhor, vulnerabilidade em relação ao fornecedor (DELFINO, 2000, p.46).

Surge, portanto, a sociedade de consumo em massa onde predominam relações de consumo do tipo 'adesão', isto é, os consumidores são obrigados a aceitar as condições unilateralmente impostas pelos fornecedores dos bens e serviços que estão adquirindo, sem que possam discutí-las.

Ao longo do tempo, tais relações demonstraram claramente a hipossuficiência do consumidor. Antes de 1990, estes, para reclamar seus direitos, teriam que se utilizar das normas previstas no Código Civil (CC) e no Código Comercial (CCom), que os igualavam aos fornecedores, pois seus postulados jurídicos eram a liberdade e a autonomia de vontade.

Entretanto, esse arcabouço jurídico de cunho liberal não disciplinava adequadamente as relações jurídicas de consumo, a sociedade clamava por normas que efetivamente pacificassem os conflitos e protegessem o consumidor que era a parte economicamente mais fraca.

Novamente, clamava-se pela intervenção do Estado na defesa dos entes mais fracos, em especial nas relações de consumo, para que pudesse regulálas adequadamente com vistas ao equilíbrio jurídico dos participantes e o resguardo do interesse público.

A promulgação da Constituição Federal (CF) de 1988 inseriu a defesa do consumidor, no âmbito constitucional, entre os direitos e deveres individuais e coletivos ao estabelecer no art. $5^{\circ}$, inciso XXXII que "o Estado promoverá, na forma da lei, a defesa do consumidor" e também a elevou à categoria de princípio geral da atividade econômica (art.170, inciso $\mathrm{V}$ da CF). 
Finalmente, em 1990 houve a consolidação dos Direito do Consumidor através da edição do Código de Defesa do Consumidor (CDC), Lei 8.078 de 11 de novembro de 1990. De acordo com Delfino (2000, p.46), "passou-se a dar um tratamento desigual aos desiguais, tudo em busca de equilibrar a situação diferenciada que se encontravam pólos da relação de consumo [...] somente assim seria possível o alcance do equilíbrio e da harmonia social".

\section{A Defesa do Consumidor como Ramo do Direito}

O Código de Defesa do Consumidor passou a regular de modo inovador as relações de consumo. Estabeleceu basicamente os princípios públicos das relações de consumo; os direitos básicos dos consumidores; as normas processuais adequadas à realidade moderna de proteção das massas; as práticas e as cláusulas que são consideradas abusivas e a proteção contratual; e, finalmente, as linhas norteadoras da responsabilidade civil, administrativa e penal do consumo.

Criou-se um microssistema de normas jurídicas de ordem pública, de caráter cogente e interesse social para proteção do consumidor, isto é, o CDC representa um estatuto de normas que regulamenta as relações jurídicas de consumo sob diversos prismas: do direito material, do direito processual, das sanções administrativas, das sanções penais, etc.

Segundo Dourado Gusmão (apud EFING,1999, p.38), a norma cogente é:

Norma inderrogável pelas partes, o que constitui um limite à autonomia da vontade das mesmas, isto é, à liberdade contratual. Normas assim conceituadas tutelam o interesse social e adentram na esfera do direito privado. [...] Normas de ordem pública [são] aquelas que disciplinam instituições jurídicas fundamentais e tradicionais, bem como as que garantem a segurança nas relações jurídicas.

Efing (1999, p.38) conclui que a qualificação de uma norma jurídica como de natureza cogente, de ordem pública e de interesse social, corresponde a dizer que possui um caráter de comando ou proibição e visa preservar a seguridade das relações jurídicas, atendendo ao interesse social.

Conforme defende Polastro (2000, p.08):

O Código estabeleceu, sob o aspecto penal, a tipificação de figuras delituosas e respectivas sanções; sob o aspecto material, a declaração de direitos, definição de política própria, enumeração e sancionamento de práticas abusivas, reparação de danos de caráter material e moral e institucionalização e controle de contratos de adesão. Já do ponto de vista processual, descreveu-se, na norma, a facilidade de acesso à justiça como direito básico, ampliação dos poderes do juiz com a inversão do ônus da prova, desconsideração da personalidade jurídica para atingir o patrimônio dos maus fornecedores, legitimação de entidades para a defesa coletiva, dispensa do pagamento de custas e ampliação dos efeitos da coisa julgada.

A expressão microssistema foi criada pelo italiano Natalino Irti para designar leis que não se limitam a certas matérias, mas possuem regras de direito civil, administrativo, processual e penal. Com esta construção doutrinária, ele pretende demonstrar "que cada microssistema se [fecha] em si mesmo, sendo auto-suficiente do ponto de vista hermenêutico, já que cada estatuto traz normalmente os próprios princípios interpretativos" (NOVAIS, 2001, p.149).

A maioria dos doutrinadores brasileiros considera o CDC como um microssistema conforme a concepção de Natalino Irti.

Bulgarelli (apud NOVAIS, 2001, p.149) dispõe claramente sobre esta posição:

De um ponto de vista normativo, [...] verifica-se que se trata de uma lei completa, quase autônoma, com incursões no Direito privado, no campo administrativo, no plano processual e na órbita penal, o que se verifica pelos 119 artigos, no que o enquadra naqueles diplomas legais caracterizados pela doutrina moderna, como um microssistema legal autônomo.

Nesse sentido, o Direito do Consumidor segue a tendência atual de adoção de microssistemas jurídicos reguladores de relações específicas, como é o caso 
das relações de consumo que possuem particularidades sui generis.

Assim, outros ramos do direito não regulariam adequadamente tais relações e somente deveriam incidir no âmbito do Direito do Consumidor para suprir lacunas porventura existentes.

O Direito do Consumidor é um direito especial a regular situações especiais: as relações jurídicas de consumo. Entretanto, Efing (1990, p.27) entende que não se trata de "[...] uma ciência nova dentro da ciência do direito, mas sim uma subdivisão do mesmo, para melhor elaboração e compreensão das normas que devem regular relações fáticas especiais".

$\mathrm{Na}$ verdade, tem-se uma autonomia didática do Direito do Consumidor, pois há vasta matéria a receber um estudo específico, princípios próprios, conceitos, teorias, etc. Tudo isso decorrente da especificidade da relação jurídica de consumo, dos sujeitos a ela inerentes (fornecedor e consumidor) e do objeto da relação (produto ou serviço).

Quando o CDC preceitua o estabelecimento de normas de ordem pública e interesse social para reger as relações de consumo, quer o legislador proporcionar o equilíbrio dentro do qual o consumidor possa se equiparar ao fornecedor [...]. Portanto, o CDC, ao elencar normas impositivas de ordem pública e interesse social, sobrepõe-se à vontade das partes, no intuito de promover a defesa do consumidor, não cabendo às partes da relação de consumo a derrogação de tais preceitos cogentes nele contidos.(EFING, 1990, p.38).

Desse modo, o Direito do Consumidor surge como um ramo jurídico inovador porque, através de normas públicas e cogentes, visa intervir nas relações privadas de consumo, equilibrando-as e buscando a pacificação social.

\section{Direito do Consumidor e Garantias Constitucionais}

O Código de Defesa do Consumidor encontra-se em plena consonância com os princípios, direitos e garantias fundamentais do cidadão inseridos na Constituição Federal de 1988.
O CDC em seu art. $1^{\circ}$ estabelece que as normas de proteção do consumidor são de ordem pública e de caráter cogente com o predomínio do interesse social, conforme dispõem os arts. $5^{\circ}$, inciso XXXII e 170, inciso $\mathrm{V}$ da CF e art.48 do Ato das Disposições Constitucionais Transitórias (ADCT).

O capítulo II do Título I trata da Política Nacional de Relações de Consumo estabelecendo as diretrizes norteadoras de todo o sistema. $\mathrm{O}$ art. $4^{\circ}$ do $\mathrm{CDC}$ consagra o respeito à dignidade dos consumidores, sua saúde e segurança, a proteção de seus interesses econômicos, melhoria de sua qualidade de vida, transparência e harmonia das relações de consumo em conformidade aos princípios constitucionais da dignidade da pessoa humana (art. $1^{\circ}$, inciso III da CF), da cidadania (art. $1^{\circ}$, inciso II da CF), da isonomia, do direito à vida, saúde, à liberdade, à segurança e à propriedade (art. $6^{\circ}$, caput da CF).

A proteção dos interesses econômicos e a melhoria na qualidade de vida (art. $4^{\circ}$ do CDC) encontram amparo na Constituição Federal que no art. $3^{\circ}$ traça como objetivos fundamentais da República a garantia do desenvolvimento nacional (inciso II) e a erradicação da pobreza e da marginalização (inciso III).

A política nacional de consumo também está em consonância com o art.170 da Constituição Federal (Título VII - Da Ordem Econômica e Financeira) que estabelece os princípios gerais da atividade econômica, com especial destaque para: função social da propriedade (inciso III); livre concorrência com respeito ao consumidor (inciso IV); defesa do meio ambiente lato sensu (inciso VI); redução das desigualdades regionais e sociais (inciso VII); busca do pleno emprego (inciso VIII), etc. de modo que nas relações de consumo predomine a proteção do consumidor e a sua dignidade.

$\mathrm{O}$ art $4^{\circ}$ do CDC estabelece também os princípios norteadores do Direito do Consumidor que serão melhor detalhados na seção seguinte.

É garantido ao consumidor a prestação de serviços públicos com qualidade (art. $4^{\circ}$ inciso VII do 
$\mathrm{CDC}$ ); adequação e eficiência (art. $6^{\circ}$ inciso $\mathrm{X}$ do CDC); segurança e continuidade (art.22 do CDC), atendendo às garantias e direitos constitucionais previstos nos arts $.5^{\circ}, 6^{\circ}, 37$ e $\S 2^{\circ}$ do art. 170 da CF, entre outros.

A proteção do consumidor na CF encontra-se de modo explícito no art.24 inciso VIII que trata da competência concorrente da União, Estados e Distrito Federal para legislar sobre responsabilidades por dano ao consumidor e no art.176, parágrafo único, que dispõe sobre o regime de concessão e permissão dos serviços públicos, direitos dos usuários, política tarifária e manutenção de serviço adequado.

O CDC possui vasta disposição a respeito de acesso à justiça quando houver violações do Direito do Consumidor, encontra-se assim discriminada:

a) art. $5^{\circ}$ : assistência jurídica integral e gratuita (inciso

I); criação de promotorias de justiça no âmbito do Ministério Público (inciso II); criação de delegacias de polícia especializadas em infrações penais de consumo (inciso III); criação de Juizados Especiais e Varas especializadas na solução de litígios de consumo (inciso IV); estímulo ao desenvolvimento de Associações de Defesa do Consumidor (inciso V);

b) art. $6^{\circ}$ : acesso aos órgãos judiciários e administrativos para prevenção ou reparação de danos patrimoniais e morais (inciso VII); facilitação da defesa de seus direitos com a inversão do ônus da prova a seu favor (inciso VIII);

c) o título III do CDC: trata da defesa do consumidor em Juízo, trazendo disposições gerais (capítulo I, arts.81 a 90); ações coletivas para a defesa dos interesses do consumidor (capítulo II, arts.91 a 100); ações de responsabilidade do fornecedor de produtos e serviços (capítulo III, arts.101 e 102); coisa julgada (capítulo IV, arts.103 e 104); etc.

Toda essa matéria encontra-se em consonância com a Constituição Federal, em especial no disposto nos art. $5^{\circ}$ inciso XXXIV, alínea "a"; incisos XXXV e LXXIV; art.93 inciso IX e arts.127, 129 e 134.
Portanto, verifica-se a efetiva consonância dos princípios e normas do CDC aos direitos e garantias fundamentais resguardados na $\mathrm{CF}$; de modo que as normas consumeristas se integram harmonicamente ao sistema jurídico constitucional e ao ordenamento jurídico como um todo.

\section{Princípios do Código de Defesa do Consumidor}

Bandeira de Mello (apud CUNHA, 1999, p.60) afirma que:

[...] princípio é mandamento nuclear de um sistema, verdadeiro alicerce, disposição fundamental que se irradia sobre diferentes normas compondo-lhes o espírito e servindo de critério para sua exata compreensão e inteligência, exatamente por definir a lógica e a racionalidade do sistema normativo, no que lhe confere a tônica e lhe dá sentido harmônico [...] violar um princípio é muito mais grave que transgredir uma norma, pois é ofensa não apenas a um específico mandamento obrigatório, mas a todo o sistema de comandos.

Nesse sentido, o CDC deve ser aplicado pelos operadores do direito respeitando sempre seus princípios norteadores, que, por sua vez, estão em consonância com a Constituição Federal e os princípios gerais do direito, pois sua violação, conforme demonstrado, implica na violação do ordenamento jurídico como um todo.

$\mathrm{O}$ art. $4^{\circ}$ estabelece que os princípios da defesa do consumidor e a livre iniciativa, oriundos do princípio constitucional geral da ordem econômica (art.170 da CF), devem estar harmonizados nas relações de consumo, mas a estes são acrescidos os da equidade e da boa-fé, pois constituem a base desse sistema jurídico. Os princípios gerais das relações jurídicas de consumo encontram-se dispostos nos $\operatorname{arts} .1^{\circ}$ a $7^{\circ}$ do CDC.

\section{Princípio da Estatização do Direito do Consumidor}

O Estado passa a interferir mais diretamente nas relações de consumo (embora de caráter privado), 
visando ao bem comum e à pacificação social (art. $1^{\circ}$ do CDC).

Tem-se uma maior intervenção do Estado nessas relações, através de normas cogentes, de ordem pública e de interesse social. A ordem constitucional após 1988 impunha a mudança de um Estado Liberal para um Estado Social com novas feições, voltado para a tutela dos entes mais fracos e isso se refletiu significativamente no CDC.

\section{Princípio da Isonomia ou Vulnerabilidade do Consumidor}

Pressupõe que na relação jurídica o consumidor é a parte mais fraca, é hipossuficiente técnica e/ou economicamente, devendo ser protegido pelo sistema normativo (art. $4^{\circ}$ do CDC).

O princípio da isonomia assegurado constitucionalmente se reflete no subsistema jurídico do CDC, prevendo o tratamento desigual aos desiguais na medida de sua desigualdade.

Nery Junior (apud CUNHA, 1999, p.63):

Para atender ao princípio da isonomia $\left(\mathrm{CF}, 5^{\circ}\right.$, caput), o CDC criou vários mecanismos para fazer com que se possa alcançar a igualdade real entre fornecedor e consumidor [...] São exemplos de aplicação da isonomia pelo texto do CDC: a inversão do ônus da prova em favor do consumidor (CDC, $6^{\circ}$, VIII); a interpretação dos contratos de consumo em favor do consumidor (CDC, 47); a eficácia erga ommes da coisa julgada na ação coletiva para defesa dos direitos individuais homogêneos, quando procedente o pedido (in utilibus) (CDC, 103).

Portanto, os consumidores serão tratados desigualmente na medida de sua desigualdade para que se tenha uma igualdade substancial e não meramente formal. Tal fato será proporcionado pela própria norma consumerista que será responsável pela equalização, na relação de consumo, da vulnerabilidade do consumidor.

\section{Princípio da Transparência e Harmonia}

O fornecedor deve agir com lealdade ao consumidor, apresentando-lhe de forma clara todas as características, as qualidades e as vantagens do produto ou serviço que está fornecendo (art. $4^{\circ}$, caput do $\mathrm{CDC})$.

Deve predominar a harmonia na relação jurídica entre fornecedor e consumidor, havendo total clareza nas informações e nas condições pactuadas.

Os arts.30, 31, 46 e 54, $\S 3^{\circ}$ do CDC impõem o dever geral de informação, objetivando relações jurídicas de consumo mais sinceras que satisfaçam os entes envolvidos.

De acordo com Cunha (1999, p.72), “a transparência implica uma relação contratual mais equilibrada entre consumidor e fornecedor, por meio da informação correta sobre o produto ou serviço, que deve coadunar-se com o contrato pactuado e a lealdade entre as partes envolvidas na relação de consumo, mesmo na fase pré-contratual".

\section{Princípio do Equilíbrio entre as Partes}

O consumidor é protegido pela norma jurídica porque é a parte mais fraca e vulnerável, assim, manter-se-á o equilíbrio da relação jurídica de consumo (art. $4^{\circ}$ inciso III do CDC).

Em face da hipossuficiência do consumidor, esse princípio consumerista, com fulcro na isonomia do art. $5^{\circ}$ da Constituição Federal, o equipara legalmente ao fornecedor com vistas a inserir um equilíbrio substancial na relação jurídica de consumo.

\section{Princípio da Boa-Fé Objetiva}

Estabelece que deve haver um modelo de conduta social baseado na lealdade e no respeito aos direitos do consumidor (art. $4^{\circ}$, inciso III do CDC).

Martins Costa (apud POLASTRO, 2000, p.7) afirma que "por boa-fé objetiva se quer significar [...] modelo de conduta social, arquétipo ou standard 
jurídico segundo o qual cada pessoa deve ajustar sua conduta".

Esse princípio impõe ao fornecedor agir de forma transparente e leal, fornecendo informações precisas e corretas sobre os produtos e serviços, enfim, agindo dentro de um modelo de conduta social baseado na boa-fé objetiva.

\section{Princípio da Responsabilidade Objetiva}

$\mathrm{O}$ fornecedor tem a responsabilidade de reparar o dano decorrente do fornecimento de produto ou serviço (arts.12 e 18 do CDC) não sendo necessário apurar a ocorrência de culpa, pois a atividade econômica exercida impõe um risco ao fornecedor (teoria do risco).

No Código do Consumidor foi adotado o sistema civil de responsabilidade objetiva, somente sendo admitido a responsabilidade subjetiva, isto é, mediante apuração de culpa, de forma excepcional (art.14, § $4^{\circ}$ do CDC no caso de profissionais liberais).

Foram adotadas duas vertentes de responsabilidade civil: a do fato do produto ou serviço (vício extrínseco ou causador de um acidente de consumo) e a do vício do produto ou serviço (vício intrínseco, em face de um defeito notório, de fácil constatação ou oculto). Aquela, por inadequação decorrente da insegurança que o produto ou serviço proporciona ao consumidor; esta, por inadequação que encontra na impropriedade econômica (compreendendo-se aqui a funcionalidade e a destinação) do produto ou do serviço.

A responsabilidade objetiva também atinge os danos causados por publicidade enganosa ou abusiva.

\section{Princípio da Proibição de Cláusulas Abusivas}

Esse princípio assegura ao consumidor a proteção contra cláusulas abusivas (art. $6^{\circ}$ inciso IV do CDC), consideradas nulas de pleno direito (art.51 do CDC) e enumera um rol não taxativo das mesmas (numerus apertus).
Cláusulas abusivas "são aquelas notoriamente desfavoráveis à parte mais fraca na relação contratual de consumo. São sinônimas de cláusulas abusivas as expressões cláusulas opressivas, onerosas, vexatórias ou, ainda, excessivas" (NERY JUNIOR apud CUNHA, 1999, p.67).

As cláusulas abusivas são nulas de pleno direito, significando que a nulidade deve ser reconhecida judicialmente, por meio de ação direta ou reconvenção, contestação, ou mesmo de ofício pelo juiz.

\section{Princípio da Educação e da Informação}

Consumidores e fornecedores devem ter acesso à educação e à informação acerca de seus direitos e deveres na atual sociedade de consumo em massa (art. $4^{\circ}$ incisos III e IV do CDC). A informação adequada é um direito básico do consumidor $\left(\operatorname{art} .6^{\circ}\right.$ incisos II, III e IV). Há a proibição da enganosidade e abusividade na divulgação de produtos e serviços (art.36 e 38).

O CDC regulou a publicidade (e não a propaganda) de modo que somente terá controle sobre a veiculação comercial que visa ao convencimento para aquisição de produto ou serviço, não tendo qualquer controle sobre a veiculação de idéias de cunho político, religioso, ético ou moral. O controle da publicidade visa evitar o dano ou abuso do direito do consumidor através dos princípios norteadores da identificação da mensagem publicitária que são: da vinculação contratual da publicidade (art.36); da veracidade (art.30); da não-abusividade da publicidade ( $\operatorname{art} .37, \S 1^{\circ}$ e $2^{\circ}$ ); do ônus da prova pelo fornecedor (art.38) e da correção do desvio publicitário (art.56 inciso XII).

Os princípios indicam que a informação é um dever dos fornecedores que não é satisfeito pela publicidade que apenas possui fins comerciais. Portanto, a informação deve se pautar na lealdade, na honestidade e boa-fé.

A análise dos princípios do CDC é significativa para a compreensão da aplicabilidade das normas 
consumeristas e não se deve restringir àqueles apresentados. Como se verificou, o microssistema jurídico do CDC é extremamente complexo e impõe um estudo continuado e intenso para que seja utilizado adequadamente pelos operadores do direito.

\section{A Relação Jurídica de Consumo e seus Elementos}

Apontam-se algumas definições de relações jurídicas de consumo de diferentes doutrinadores:

Nery Junior (apud EFING, 1999, p.26) afirma que "entende-se por relação de consumo a relação jurídica entre 'fornecedor' e 'consumidor' tendo como objeto o 'produto' ou o 'serviço'”.

De acordo com Cretella Junior (apud EFING, 1999, p.26), a relação jurídica de consumo é assim definida:

É a relação jurídica que se forma entre fornecedor e consumidor, devendo, esse último, ser pessoa física ou jurídica adquirente ou utente, de produto ou serviço, como destinatário final, equiparando-lhe a coletividade de pessoas, ainda que indetermináveis, desde que passe a integrar essa relação.

Efing (1999, p.26) entende "por relação de consumo, objeto do regramento instituído pelo CDC, a relação jurídica estabelecida entre consumidor(es) e fornecedor(es) segundo as conceituações do CDC, tendo por objeto produto ou prestação de serviço".

A partir das diferentes definições apresentadas, podese afirmar que a relação jurídica de consumo é uma espécie de relação jurídica com características específicas, pois somente se consolida ao serem preenchidos requisitos (subjetivos e objetivos) relacionados ao vínculo. Há sujeitos de direito em pólos opostos da relação que interagem entre si, visando à obtenção da finalidade que originou a relação.

Os requisitos necessários são:

a) um sujeito ou ente despersonalizado que se enquadre na situação jurídica de fornecedor; b) existência no pólo oposto da relação jurídica de um sujeito de direito que se enquadra na situação jurídica de consumidor;

c) que o objeto da relação jurídica seja um produto ou um serviço.

Caso não esteja presente algum desses requisitos, a relação jurídica não será de consumo, mas de outra espécie: civil, comercial, trabalhista, etc. e não estará sujeita às normas previstas no Código de Defesa do Consumidor.

Nesse sentido, é de suma importância o reconhecimento da existência ou não de uma relação jurídica de consumo através da análise dos elementos que a configuram. A seguir, proceder-se-á ao estudo de cada um dos referidos elementos.

\section{Conceito de Consumidor}

A conceituação de consumidor permite que se delimite, em termos jurídicos, os indivíduos ou entes que serão tutelados pelo Código de Defesa do Consumidor, estabelecendo também os limites da aplicabilidade das normas consumeristas.

O CDC adotou quatro conceitos de consumidor:

a) o padrão ou standard (destinatário final) no $\operatorname{art} .2^{\circ}$, caput;

b) a coletividade de pessoas (ainda que indetermináveis) no art. $2^{\circ}$, parágrafo único;

c) as vítimas de acidente de consumo no art.17;

e) aqueles expostos às práticas abusivas no art.29.

Será realizada a análise de cada um desses artigos para melhor compreensão dos institutos jurídicos.

\section{Consumidor Padrão}

$\mathrm{O}$ artigo art. $2^{\circ}$, caput do CDC dispõe que "consumidor é toda pessoa física ou jurídica que adquire ou utiliza produto ou serviço como destinatário final". 
Esse conceito é constituído por três elementos:

a) elemento subjetivo: o sujeito que pode ser pessoa física ou jurídica;

b) elemento objetivo: o objeto que será produto ou serviço adquirido;

c) elemento teleológico: a finalidade que se caracteriza pela destinação conferida ao objeto (produto ou serviço). Deverá ser sempre finalística, ou seja, representa a retirada do objeto do mercado e sua total fruição de modo que se encerre seu ciclo econômico, não havendo revenda ou qualquer outra destinação intermediária.

O consumidor poderá ser pessoa física (o ser humano) ou pessoa jurídica de qualquer tipo, pois a norma não faz distinção, incluindo a microempresa, a multinacional, a pessoa civil ou comercial, etc.

Consumidor é aquele que adquire ou utiliza produto ou serviço. Adquirir significa obter, comprar; já utilizar significa usar, tirar utilidade de, "servir-se". Portanto, consumidor não é somente aquele que compra, mas também aquele que consome sem ter adquirido.

Conforme afirma Rizzato Nunes (apud DELFINO, 2000, p.47) "a norma define como consumidor tanto quem efetivamente adquire (obtém) o produto ou o serviço, como aquele que, não tendo adquirido, utiliza-o (usa-o) ou o consome".

O consumidor também será definido pelo elemento teleológico (finalidade), ou seja, a aquisição do produto ou serviço como "destinatário final".

O termo destinatário final deve indicar a aquisição ou utilização do produto ou serviço para fruição total (destruição). Representa a sua retirada do mercado e o encerramento da cadeia econômica, portanto, não haverá revenda ou comercialização dos mesmos. Tal termo não ficará adstrito ao uso do produto ou serviço e sim à verificação do encerramento do ciclo econômico, de modo que não se vise futuro comércio.

Almeida (apud DELFINO, 2000, p.48) afirma que:
Pela definição legal de consumidor, basta que ele seja o 'destinatário final' dos produtos ou serviços (CDC, art. $2^{\circ}$ ), não incluindo aí apenas aquilo que é adquirido ou utilizado para uso pessoal, familiar ou doméstico, mas também o que é adquirido para o desempenho de atividade ou profissão, bastando, para tanto, que não haja finalidade de revenda.

Desse modo, o consumidor destinatário final é aquele que retira o produto e o serviço do mercado (encerramento da cadeia econômica), não se considerando o uso que será feito do bem. Este é o sentido da definição legal de consumidor prevista no $\operatorname{art.} 2^{\circ}$, caput do CDC, não se exigindo, como em algumas legislações alienígenas, o uso nãoprofissional dos bens.

\section{Coletividade Consumidora}

O parágrafo único do art. $2^{\circ}$ do CDC dispõe que "equipara-se a consumidor a coletividade de pessoas, ainda que indetermináveis, que haja intervindo nas relações de consumo".

O CDC, ao equiparar a coletividade ao consumidor, impôs novas formas de defesa de atos, pois o ordenamento jurídico, quase em sua totalidade, se associa à uma tutela específica direcionada a um titular respectivo.

A evolução social trouxe ao mundo jurídico novas necessidades dos indivíduos e surgiram conflitos que envolviam a sociedade de massa. Logo, ao legislador, impôs-se a criação de novos instrumentos processuais e institutos jurídicos capazes de tutelar adequadamente essas situações.

Portanto, o CDC confere à coletividade de pessoas, ainda que indetermináveis, a mesma proteção concedida ao consumidor individualmente. "Reconhece-se à coletividade o direito de ver seus interesses protegidos, não mais individual, mas sim, considerando-se a universidade, o conjunto de consumidores de produtos ou serviços ou mesmo grupo, classe ou categoria deles." (DONATO apud DELFINO, 2000, p.49) 
O parágrafo único do art. $2^{\circ}$ trouxe ampliação do conceito de consumidor padrão, abrangendo toda a coletividade, determinável ou indeterminável, desde que tenha intervindo na relação de consumo. É uma extensão do caput do art. $2^{\circ}$, ampliando somente o elemento subjetivo (o sujeito consumidor), mas os elementos objeto e finalidade continuam válidos $\mathrm{e}$ presentes. Assim, a coletividade receberá a tutela consumerista se adquiriu ou utilizou produtos ou serviços como destinatário final.

\section{Consumidor Vítima de Acidente de Consumo}

$\mathrm{O}$ art.17 do CDC prescreve que "para os efeitos desta Seção [Da responsabilidade pelo fato do produto e do serviço], equiparam-se aos consumidores todas as vítimas do evento".

Segundo Donato (apud EFING, 1999, p.53):

Trata-se nessa seção de novo âmbito de tutela do consumidor: a vítima do acidente de consumo que, em virtude do disposto no art., passa a ser equiparado ao consumidor. Desconsidera-se a partir desse momento, se o tutelado, ou consumidor, qualifica-se como destinatário final do produto ou serviço; se houve a participação na relação de consumo ou não [...]. Mostra-se suficiente que a vítima, para que seja equiparada ao consumidor, tenha sido atingida em sua esfera jurídica pelos efeitos do acidente de consumo, [...] atingida em sua incolumidade físico-psíquica ou sua incolumidade econômica.

Verifica-se, que no artigo17, há a equiparação das vítimas de acidente de consumo que não tiveram participação, direta ou indireta, na relação de consumo, aos consumidores padrão previstos no art. $2^{\circ}$ do CDC.

Não é necessário que a vítima do evento danoso, oriundo do fato do produto ou do serviço, tenha participado (direta ou indiretamente) da relação de consumo, mas é indispensável que tal relação seja preexistente, mesmo que a vítima a desconheça.

\section{Consumidor Exposto às Práticas Comerciais}

O art.29 do CDC ampliou significamente o conceito de consumidor, pois estabelece que "equiparam-se aos consumidores todas as pessoas determináveis ou não expostas as práticas nele previstas".

Para Lima Marques (apud EFING, 1999, p.57):

$\mathrm{O}$ art.29 supera, portanto, os estritos limites da definição jurídica de consumidor para imprimir uma definição de política legislativa! Parece-nos que, para harmonizar os interesses presentes no mercado de consumo, para reprimir eficazmente os abusos do poder econômico, para proteger os interesses econômicos dos consumidores finais, o legislador concedeu um poderoso instrumento nas mãos daquelas pessoas (mesmos agentes econômicos) expostas às práticas abusivas. Estas, mesmo não sendo 'consumidores stricto sensu', poderão utilizar das normas especiais do $\mathrm{CDC}$, de seus princípios para combater as práticas comerciais abusivas.

É considerado consumidor qualquer pessoa exposta às práticas comerciais previstas no capítulo $\mathrm{V}$ do $\mathrm{CDC}$ relativas à oferta, publicidade, práticas abusivas, cobrança de dívidas, bancos de dados e cadastros de consumidores e também da proteção contratual (capítulo VI) que envolve cláusulas abusivas e contratos de adesão. Basta a exposição das pessoas (consumidores equiparados) a essas práticas de enorme potencial lesivo, não se exigindo a comprovação do efetivo dano e haverá a tutela do CDC.

No caso específico desse artigo, incluem-se os intermediários e os comerciantes que expostos a essas práticas terão a proteção do $\mathrm{CDC}$, pois a própria lei determina "todas as pessoas" não fazendo qualquer tipo de ressalva.

Não há qualquer diferença, para efeitos da aplicabilidade do CDC, entre os consumidores equiparados do art.29 e os outros consumidores conceituados no art. $2^{\circ}$, caput e parágrafo único $\mathrm{e}$ art.17 do CDC. Atualmente, o art.29 é norma muito importante, pois estende o campo de aplicação do CDC. 


\section{Conceito de Fornecedor}

Fornecedor é toda pessoa física ou jurídica, bem como os entes despersonalizados - assim entendidos sociedade de fato, sociedade irregular, condomínio, consórcio, espólio, massa falida, etc. - de Direito Público ou Privado, nacional ou estrangeiro, que desenvolvem atividades de produção, montagem, criação, construção, transformação, importação, exportação, distribuição ou comercialização de produtos ou prestação de serviços (art. $3^{\circ}$, caput do CDC).

A noção de fornecedor não se limita ao fabricante, ao produtor ou ao comerciante, incluindo também outras espécies: o montador, o criador, o construtor, o transformador, o importador, o exportador, o distribuidor, enfim, todo aquele que, de qualquer forma, executa atividade de transmissão de produtos ou serviços no mercado de consumo.

O intermediário não foi literalmente previsto na legislação consumerista, mas o entendimento doutrinário que a expressão fornecedor consagrada no art. $3^{\circ}$ do CDC o abrange também, uma vez que ele transfere o produto ou serviço a outrem no próprio mercado de consumo.

Portanto, o conceito de fornecedor abrange somente aqueles que fornecem produtos ou serviços no mercado de consumo com habitualidade mercantil, visando o lucro e com caráter de profissionalidade.

Os entes despersonalizados também são fornecedores, apesar de formalmente não serem pessoas jurídicas, pois lhes falta a affectio societatis (intenção expressa de manter vínculo associativo).

A intenção do legislador foi ampliar o conceito de fornecedor, incluindo neste os entes despersonalizados.

Inclui-se na definição de fornecedor as pessoas jurídicas privadas como as fundações (patrimônio personalizado afetado a um fim) e as corporações (conjunto de pessoas, personalizado, dirigido a um fim) que podem ser de direito privado ou de direito público (CRETELLA JUNIOR apud EFING, 1999, p.60).
Por 'atividade' entende-se a "prática reiterada de atos negociais, de modo organizado e unificado, por um mesmo sujeito, visando uma finalidade econômica unitária e permanente (atividade negocial)" (BARROS LEÃES apud EFING, 1999, p.61).

O CDC elenca as atividades de modo específico:

a) produção é a elaboração produtiva do bem, móvel ou imóvel, material ou imaterial;

b) montagem é a combinação de peças para a formação do produto;

c) criação é a elaboração produtiva que produz um bem novo (novidade);

d) transformação é a alteração da estrutura ou forma de um produto já existente, transformando-o em outro;

e) importação é a aquisição de produtos no exterior;

f) exportação é o envio de produtos ao exterior;

g) distribuição é a concretização da tradição da coisa;

h) comercialização é a prática habitual de atos de comércio, em especial compra e venda.

\section{Conceito de Produto}

Produto é qualquer bem, móvel ou imóvel, material ou imaterial. Brito Filomeno (apud EFING, 1999, p.65) afirma que seria mais adequado utilizar-se do termo bem ao invés de produto, pois aquele é mais técnico, tanto do ponto de vista jurídico quanto da economia política. Além disso, o bem é o objeto da relação jurídica de consumo, intermediando os dois sujeitos (consumidor e fornecedor) da mesma.

Efing (1999, p.67, nota de rodapé 72) forneceu um caso interessante em que houve a aplicação do CDC, demonstrando a abrangência do termo produto/ bem que se estende até aos animais:

Em Pato Branco-PR, ocorreu um fato pitoresco, registrado pelo Deacon, onde um consumidor 
sentiu-se lesado com a aquisição de uma vaca leiteira, pois constatou, após a tradição, que a mesma não produzia leite algum, o que ensejou a reclamação junto ao Deacon, obtendo o desfazimento do negócio, sendo-lhe restituído o valor pago. Assim, observase que o 'produto da pecuária' - semovente - é que foi, exatamente, o objeto da relação de consumo para destinatário final.

Portanto, verifica-se que o conceito de produto definido no $\S 1^{\circ}$ do art. $3^{\circ}$ do CDC é muito amplo, pois envolve as grandes classificações de bens existentes no Direito: bens móveis e imóveis, materiais e imateriais.

A intenção do legislador foi recepcionar pelas normas consumeristas um número significativo de bens (objeto das relações de consumo) para a ampla proteção do consumidor. $\mathrm{O}$ termo bem é utilizado em sentido econômico, isto é, como fruto do trabalho humano, suscetível de valorização econômica, estando disponível à aquisição ou à apropriação (res in commercio) e visando à satisfação da necessidade daquele que $o$ adquiriu.

\section{Conceito de Serviço}

Dispõe o $\operatorname{art} .3^{\circ} \S 2^{\circ}$ do CDC que "serviço é qualquer atividade fornecida no mercado de consumo, mediante remuneração, inclusive os de natureza bancária, financeira, de crédito e securitária, salvo decorrentes das relações de caráter trabalhista".

Verifica-se que, para efeito das relações de consumo, somente se considera o serviço remunerado que implica numa onerosidade ao consumidor. Entretanto, o CDC não trata apenas da remuneração direta, ou seja, o pagamento feito diretamente pelo consumidor ao fornecedor; incluindo também a remuneração indireta advinda da prestação de serviços aparentemente gratuita, mais que possui a remuneração embutida nos custos.

Segundo Mukai (apud EFING, 1999, p.69), "para se caracterizar serviço, para efeito de incidência do CDC, basta que a atividade desenvolvida seja remunerada, ainda que 'esporádica' e não habitual".
Nessa definição de serviço, inclui-se tanto o serviço privado quanto o serviço público, mesmo que executado por entidade particular através do regime jurídico da concessão ou da permissão.

Apenas exclui-se da incidência do CDC os serviços oriundos das relações de caráter trabalhista que possuem disciplinamento próprio na Consolidação das Leis Trabalhistas (CLT).

\section{Aplicabilidade do Código de Defesa do Consumidor às Operações Bancárias}

Atualmente, vive-se sob a égide do chamado capitalismo financeiro em que a sociedade moderna é altamente dependente das instituições bancárias e financeiras, que detêm a concentração dos recursos necessários ao fomento das atividades empresariais e pessoais.

Direta ou indiretamente, essas instituições estão presentes no cotidiano dos indivíduos, pois delas se utilizam para o recebimento de salários e pensões, para o pagamento dos mais diversos tipos de contas e também para a obtenção de empréstimos e financiamentos através da concessão do crédito.

Logo, não se pode negar a importância das instituições financeiras e bancárias, pois significamente inseridas no modelo de desenvolvimento econômico adotado nas sociedades contemporâneas.

\section{Crédito Bancário}

O crédito é o bem mais valioso das instituições bancárias e financeiras, pois os lucros, em sua totalidade, advêm dos contratos e procedimentos que os envolvem. Tal fato demonstra a importância do crédito na atual sociedade de consumo, como fomentador das atividades empresariais e pessoais.

A grande maioria das pessoas físicas e jurídicas não dispõe de recursos próprios para aplicar nos negócios em que atuam e, desse modo, celebram contratos de crédito junto às instituições bancárias. 
O crédito é o elemento propulsionador do sistema econômico, permitindo que os objetivos negociais sejam atingidos, logo, não se destina à criação de riquezas, mas possibilita sua circulação e acumulação.

As instituições bancárias e financeiras são os agentes legalmente habilitados para a concessão de crédito no mercado de consumo.

De acordo com Rizzardo (1999, p.16):

O banco promove a industrialização do crédito, o favorecimento da circulação de riquezas e enseja as condições de consolidação das poupanças individuais. Tem a função monetária enquanto é órgão de pagamento e creditício, ou quando age como órgão de investimento - funções que se entrelaçam e se completam. No tocante à atividade creditícia, age com recursos próprios e de terceiros, corporificados os últimos através de depósitos e conseguidos em função da confiança do público.

A palavra crédito advém do latim 'credere' que significa confiança. Com fulcro nas lições doutrinárias de Rizzardo (1999, p.19), pode-se definir o crédito como toda a operação monetária pela qual se realiza uma prestação presente contra a promessa de uma prestação futura. É característico do crédito a existência de um intervalo de tempo entre a prestação e a contraprestação correspondente, sendo indispensável a confiança daquele que fornece o crédito de que o devedor solverá sua dívida.

A atividade creditícia dos bancos é alimentada através da captação de recursos do público (poupanças individuais) e de recursos próprios. Eles somados constituem a massa dos recursos disponíveis que serão utilizados em empréstimos e financiamentos de terceiros, mediante a cobrança de juros (o 'preço' do crédito concedido).

\section{Operações Bancárias}

As atividades principais dos bancos são as operações bancárias que se desmembram em concessão de empréstimos, recebimento de depósitos, descontos e redescontos de títulos e abertura de créditos, constituindo atividades negociais entre o banco e seus usuários tuteladas juridicamente.
Destacam-se algumas características primordiais das operações bancárias apontadas por Rizzardo (1999, p.17):

a) pecuniaridade: em todas as operações estão envolvidos o dinheiro e, conseqüentemente o crédito, pois todas possuem cunho oneroso;

b) atividade em grande escala: realizadas de modo homogêneo e em grande quantidade, pois o banco para auferir lucro necessita de expressivo volume de recursos;

c) atividade em série: realizadas em massa com um número indeterminado de pessoas, obedecendo a regras bancárias uniformes e tipos negociais estandardizados;

d) complexidade: o modelo econômico atual impôs o desenvolvimento de relações econômicas sofisticadas, impondo negócios complexos entre o banco e o usuário;

e) profissionalidade: as operações bancárias são realizadas de modo habitual, são a razão de ser das instituições bancárias de modo que a intermediação do crédito é sua profissão;

f) comercialidade: as operações bancárias são caracterizadas como atos de comércio, pois possuem intermediações, habitualidade e lucro (elementos caracterizadores da atividade mercantil). O banqueiro é chamado comerciante de crédito, eis que seu negócio consiste em intermediar, com recursos obtidos de terceiros, operações em que é usado o crédito.

As operações bancárias são classificadas em fundamentais e acessórias.

As fundamentais representam a intermediação do crédito, ou seja, o recolhimento e a concessão de dinheiro. Estão subdivididas em:

a) ativas: objetivam a colocação de crédito no mercado, de modo que o banco se torna o credor do usuário, exemplo: empréstimos, financiamentos, aberturas de crédito, descontos, etc. Essas operações envolvem diretamente a concessão de 
crédito e representam o filão mais lucrativo das instituições bancárias;

b) passivas: visam à arrecadação de fundos junto ao público, de modo que o banco se torna devedor do cliente, exemplos: depósitos, contas correntes e redescontos.

Por outro lado, as operações acessórias não implicam nem concessão de crédito e nem de dinheiro, representam uma prestação de serviços secundários com vistas a atrair clientes, são exemplos: aluguel de cofres, cobrança de títulos e custódia de valores.

Sob o ponto de vista jurídico, entende-se que as operações bancárias estão sujeitas à tutela do CDC e defendem tal posição Nelson Nery Junior, Antonio Carlos Efing, Claudia Lima Marques, José Geraldo Brito Filomeno, Maria Antonieta Zanardo Donato, entre outros, mas alguns conservadores como Arnaldo Wald e Luiz Gastão Paes de Barros Leães negam essa sujeição.

Sustentam sua posição com fulcro na definição de consumidor prevista no art. $2^{\circ}$, caput do CDC (consumidor padrão) que requer a presença do elemento teleológico "destinatário final" para a configuração da relação de consumo. Afirmam que o usuário do banco não pode emprestar dinheiro como destinatário final, pois, devido à sua própria natureza, ele é utilizado para a circulação de riquezas como meio de pagamento o fomento. O usuário do banco somente seria destinatário final se guardasse o dinheiro embaixo do colchão.

Além disso, defendem que o CDC somente incidiria nos serviços bancários stricto sensu, como por exemplo: guarda de documentos, locação de cofres, etc., pois o § $2^{\circ}$ do art. $3^{\circ}$ do CDC põe-nos como objeto da relação de consumo. Desse modo, o grande filão das operações bancárias e gerador dos seus lucros astronômicos, a concessão de crédito via empréstimos e financiamentos, não receberia a tutela do CDC.

Assim, compreendendo que o conceito de consumidor estaria restringido ao conceito padrão (usuário final), concluiu Arnaldo Wald, em suma: a) que o CDC 'não se aplica às operações de produção, poupança e investimento, ou seja, [...] à captação de recursos pelas instituições financeiras, sob qualquer forma'; b) que o CDC 'também não se aplica às operações de empréstimo e outras análogas realizadas pelos bancos, pois o dinheiro e o crédito não constituem produtos adquiridos ou usados pelo destinatário final, sendo, ao contrário, instrumentos ou meios de pagamento, que circulam na sociedade e em relação aos quais não há destinatário final (a não ser os colecionadores de moedas e o Banco Central quando retira a moeda de circulação)'; c) 'nos casos de crédito ao consumidor, nos quais a instituição financeira é interveniente ou participante, em virtude da concessão de crédito vinculado à compra de bem ou à prestação do serviço, poderse-á entender que cabe aplicar-lhe o disposto no art.52 da lei, o mesmo não ocorrendo na hipótese de crédito livre ou desvinculado, e não se the aplicando, de modo algum, as demais disposições da lei do consumidor' " Essa argumentação é deveras falaciosa, pois uma análise sistêmica dos elementos da relação jurídica de consumo (consumidor, fornecedor, produto e serviço) demonstram sua inconsistência (EFING, 1999, p.62).

Aqueles que defendem a inaplicabilidade do CDC às atividades bancárias baseiam sua argumentação na análise isolada de alguns dispositivos e não no sistema como um todo. Além disso, conforme defende Efing, os conceitos existentes no CDC são meramente exemplificativos e as situações fáticas não se restringem especificamente a eles. Analisando-se o microssistema consumerista em sua totalidade, verifica-se que as instituições bancárias e financeiras estão sob sua tutela.

\section{Instituições Bancárias como Fornecedores de Produtos e Serviços}

As instituições bancárias se enquadram na definição legal de fornecedor prevista no art. $3^{\circ}$, caput do CDC, pois comercializam produtos e prestam serviços, isto é, exercem uma atividade nitidamente comercial, pois sempre, em todas as suas operações, visam lucro. 
Lima Marques (apud GLITZ, 2001, p.3) afirma que:

A caracterização do banco ou instituição financeira como fornecedor sob a incidência do CDC é hoje pacífica. [...] O CDC rege as operações bancárias, inclusive as de mútuo ou de abertura de crédito, pois relações de consumo. O produto da empresa banco é o dinheiro ou o crédito, bem juridicamente consumível, sendo, portanto, fornecedora; e o consumidor o mutuário ou creditado.

O art.119 do Código Comercial classifica o banqueiro como comerciante e as atividades bancárias como de mercancia (art.19, $§ 2^{\circ}$ do CCom). Toda sociedade anônima é considerada empresa (art.2 ${ }^{\circ}$ da Lei 6.404/76) e exerce atividades econômicas no mercado. Além disso, as instituições financeiras e bancárias somente podem ser constituídas em forma de sociedade anônima (art. $2^{\circ}$ da Lei 4.595/64). Portanto, os bancos exercem atividade econômica e visam o lucro, sendo tutelados como fornecedores pelo CDC.

O principal produto comercializado pelas instituições bancárias é o dinheiro, ou melhor, o crédito. O dinheiro é um bem juridicamente consumível - conforme o art.86 do Código Civil de 2002 - e o créditoé um bem imaterial; ambos são objeto da relação jurídica de consumo $\left(\S 1^{\circ}\right.$ do art. $3^{\circ}$ do $\mathrm{CDC}$ ).

Reforçando-se a caracterização dos bancos como fornecedores (art. $3^{\circ}$ do caput), o $\S 2^{\circ}$ do art. $3^{\circ}$ do CDC declara expressamente como serviços, fornecidos no mercado de consumo, as atividades de natureza bancária, financeira, de crédito e securitária, também objetos da relação de consumo.

\section{Consumidor nas Relações Bancárias}

Nas relações de consumo bancárias aplicam-se os quatro conceitos de consumidor já analisados anteriormente (art. $2^{\circ}$, caput e parágrafo único, art. 17 e art. 29 do CDC).

Havendo um consumidor pessoa física de um lado, um banco comercial de outro como fornecedor e a prestação de serviços bancários, tem-se uma relação jurídica de consumo.

No caso de ser pessoa jurídica, alguns doutrinadores, como Maria Antonieta Zanardo Donato, defendem que sua caracterização como consumidor dependeria da investigação da finalidade da contratação bancária e aferição de sua vulnerabilidade frente à instituição bancária. Logo, se a operação bancária efetuada pela pessoa jurídica almeja uma atividade intermediária, não haveria relação jurídica de consumo.

Efing defende uma posição contrária, adotada também no presente trabalho, de que não se deve ficar adstrito ao conceito de consumidor destinatário final (art. $2^{\circ}$, caput) e sim utilizar nas relações bancárias o conceito de consumidor exposto às práticas comerciais do capítulo V do CDC (art.29).

Isto decorre do fato de que os litígios oriundos das relações bancárias referem-se às questões contratuais, às práticas comerciais abusivas e à publicidade enganosa e, nesse caso, aplica-se o art.29 do CDC e não o art. $2^{\circ}$, caput. Portanto, a conceituação de consumidor nas relações bancárias está associada à sua exposição às práticas abusivas cometidas pelos bancos, não sendo preciso configurar a vulnerabilidade do consumidor.

Desse modo, as pessoas jurídicas nas relações bancárias poderão ser enquadradas como consumidoras, recebendo a tutela do CDC, desde que expostas às práticas abusivas comerciais realizadas pelos bancos.

A norma do art.29 da Lei 8078/90 incide nas relações bancárias de consumo, pelo fato de que quase a totalidade dos contratos bancários são de adesão (art.54 do CDC), contendo cláusulas abusivas (art.51 do CDC). Assim, a mera exposição da pessoa física ou jurídica ao contrato de adesão já estabelece a equiparação do consumidor destinatário final (art.29 do CDC). [...] No que respeita $\mathrm{o}$ art.29 e a proteção contratual, o comando legal é claro e o que equipara empresas e consumidores é a presença inaceitável da abusividade nas diversas formas que podem 
revestí-lo, seja a abusividade considerada objetivamente ou subjetivamente (EFING, 1999, p.56).

São estabelecidas relações jurídicas entre os bancos-fornecedores e os usuários-consumidores, ou seja, são celebrados contratos bancários que criam, regulam e extinguem direitos e obrigações para as partes. Portanto, tais contratos estabelecidos entre os bancos e os usuários são considerados relações jurídicas de consumo, havendo plena aplicabilidade do CDC às operações bancárias.

\section{Contratos de Crédito Bancário}

Os contratos de crédito bancário possuem natureza de contratos de adesão. Lima Marques (apud NOVAIS, 2001, p.100) define:

Contrato de adesão é aquele cujas cláusulas são preestabelecidas unilateralmente pelo parceiro contratual economicamente mais forte (fornecedor), ne variatur, isto é, sem que o outro parceiro (consumidor) possa discutir ou modificar substancialmente o conteúdo do contrato escrito.

O próprio Código de Defesa do Consumidor no art.54 definiu "contrato de adesão é aquele cujas cláusulas tenham sido aprovadas pela autoridade competente ou estabelecidas unilateralmente pelo fornecedor de produtos ou serviços, sem que o consumidor possa discutir ou modificar substancialmente seu conteúdo".

A partir das definições, pode-se traçar algumas características dessa modalidade contratual: imposição da vontade de uma das partes a outra; padronização e predeterminação das condições estipuladas; elaboração de cláusulas gerais rígidas; adesão em bloco de uma das partes a um conjunto de condições predispostas; liberdade viciada sem autonomia da vontade para estabelecer as condições contratuais.

Verifica-se também a existência de duas figuras jurídicas:

a) o predisponente: é o agente que estabelece as condições gerais e o conteúdo do contrato, o pólo ativo da relação contratual. Havendo uma relação de consumo, o predisponente será o fornecedor de produtos e serviços.

b) o aderente: é o agente que se restringe a aderir integralmente às condições preestabelecidas pelo predisponente, é o pólo passivo da relação contratual. Caracteriza-se como consumidor o aderente quando presente uma relação jurídica de consumo.

Essa modalidade de contratação surgiu da massificação das relações jurídicas contratuais, foi uma adaptação do Direito às exigências econômicas e sociais da modernidade que impôs a produção em série, o consumo em massa, a necessidade de agilidade nas negociações entre os sujeitos, etc.

De modo geral, o interessado sequer lê as cláusulas impressas, por várias razões, como falta de tempo, confiança que deposita no banco, imprudência, premência em ter o dinheiro à disposição, etc. Muito seguidamente, se as lê, não entende e nem se acha capacitado para compreender o significado jurídico. E caso se dê ao trabalho de proceder uma análise mais atenta, concluindo por discordar de alguma das imposições, não obterá resultados práticos, mesmo porque não consegue acesso perante os verdadeiros responsáveis do banco ou da empresa. Os que o atendem, simplesmente transmitem normas impessoais e comuns, nada decidindo ou alterando (RIZZARDO, 1999, p.22).

Os instrumentos são previamente impressos e uniformes para todos os usuários, havendo apenas alguns espaços em branco para o preenchimento do nome, fixação de prazo, valor mutuado, etc. Recebendo tudo pronto, cabe-lhes tão somente aceitar ou rejeitar integralmente as condições preestabelecidas, sem qualquer discussão, sendo simples aderentes. O contrato de adesão é modalidade amplamente utilizada nas operações bancárias, em especial nos contratos de crédito.

Modernamente, o contrato não é mais visto como algo estático e individual, mas como algo dinâmico e social. O Código de Defesa do Consumidor criou uma nova concepção contratual com as seguintes características fundamentais: 
a) limitação da vontade individual de contratar, prevalecendo a função social do contrato;

b) nova concepção de oferta que deve ser vinculativa e precisa ao declarar a quantidade e a qualidade do produto, havendo publicidade suficiente para apresentar e discriminar as características do produto;

c) formalismo legal na contratação visando à proteção do consumidor;

d) proibição do estabelecimento de cláusulas abusivas que são nulas de pleno direito;

e) relativização da força obrigatória dos contratos, pois será a lei que condicionará a sua execução visando aos interesses sociais, assim, há a relativização do princípio pacta sun servanda;

f) o juiz pode rever as cláusulas do contrato (rebus sic standibus), atuando como servo da lei e dos interesses sociais;

g) há a busca do equilíbrio contratual através da proteção da confiança e dos interesses legítimos do consumidor.

Com essa nova perspectiva, consolida-se juridicamente a justiça contratual, a confiança e a boa-fé, pois o contrato passa a ser o instrumento para a satisfação de necessidades individuais e coletivas.

O princípio da boa-fé objetiva exerce função importante nos contratos de adesão, como são os contratos bancários, pois é nesta modalidade que aparece os maiores abusos, pois o aderenteconsumidor não tem o poder de alterar o conteúdo de suas cláusulas.

Mandelbaum (1996, p.101) afirma que:

Através da aplicação dos princípios que regem a nova realidade contratual, busca-se a segurança jurídica, mas não através da liberdade contratual, onde imperava a supremacia da 'palavra dada' (pacta sun servanda), mas através da tutela da confiança e da boa-fé, banhadas pelo princípio da justiça contratual.
Portanto, a boa-fé objetiva na relação de consumo procura dar equilíbrio ao contrato, inclusive de crédito bancário, afastando a predominância da vontade de uma parte em detrimento da outra, estabelecendo um equilíbrio contratual entre o banco-fornecedor e o usuário-consumidor, limitando os desvios na relação contratual de consumo.

\section{Conclusão}

O Código de Defesa do Consumidor, Lei 8.078, de 11 de novembro de 1990, alterou significamente a tutela das relações jurídicas de consumo através de princípios e normas de ordem pública e de caráter cogente, prevalecendo nessas relações os interesses sociais, o império da lei sobre a autonomia da vontade individual e a proteção dos economicamente mais fracos.

Demonstrou-se que o Código de Defesa do Consumidor tutela todas as operações bancárias, pois são relações jurídicas de consumo, estando presentes seus elementos caracterizadores: fornecedores, consumidores, produtos ou serviços.

Nas relações de consumo bancárias aplicam-se os quatro conceitos de consumidor: o padrão ou standard (destinatário final) do art. $2^{\circ}$, caput; a coletividade de pessoas (ainda que indetermináveis) do art. $2^{\circ}$, parágrafo único; as vítimas de acidente de consumo (art.17) e todos aqueles expostos às práticas abusivas (art.29).

Entretanto, nas operações bancárias se utiliza mais o conceito de consumidor exposto às práticas comerciais do capítulo $\mathrm{V}$ do $\mathrm{CDC}$, pois, normalmente, os litígios oriundos das relações jurídicas bancárias referem-se às questões contratuais, às práticas comerciais abusivas e à publicidade enganosa e, nesse caso, aplica-se o art.29 do Código de Defesa do Consumidor.

Nesse sentido, como a conceituação de consumidor nas relações bancárias está associada à sua exposição às práticas abusivas, não é preciso configurar a vulnerabilidade econômica do 
consumidor. Desse modo, tanto pessoas físicas quanto pessoas jurídicas poderão ser enquadradas como consumidoras nas relações bancárias, recebendo a tutela do $\mathrm{CDC}$, desde que expostas às práticas abusivas comerciais realizadas pelos bancos.

As instituições bancárias se enquadram na definição legal de fornecedor prevista no art. $3^{\circ}$, caput do CDC, pois comercializam produtos e prestam serviços, isto é, exercem uma atividade nitidamente comercial, visando lucro.

O art.119 do Código Comercial classifica o banqueiro como comerciante e as atividades bancárias como de mercancia (art.19, $\S 2^{\circ}$ do CCom). Toda sociedade anônima é considerada empresa $\left(\operatorname{art} .2^{\circ}\right.$ da Lei $\left.6.404 / 76\right)$ e exerce atividades econômicas no mercado. As instituições financeiras e bancárias somente podem ser constituídas em forma de sociedade anônima (art. $2^{\circ}$ da Lei 4.595/ 64). Portanto, os bancos exercem atividade econômica e visam o lucro, sendo tutelados como fornecedores pelo Código de Defesa do Consumidor.

O principal produto comercializado pelas instituições bancárias é o dinheiro ou o crédito. O dinheiro é um bem juridicamente consumível conforme o art.86 do Código Civil de 2002 - e o crédito é um bem imaterial; ambos são objeto da relação jurídica de consumo conforme dispõe o $\S 1^{\circ}$, art. $3^{\circ}$ do CDC.

$\mathrm{O} \S 2^{\circ}$ do art. $3^{\circ}$ do CDC reforça a caracterização dos bancos como fornecedores, declarando expressamente como serviços fornecidos no mercado de consumo, as atividades de natureza bancária, financeira, de crédito e securitária.

Portanto, conclui-se que havendo um consumidor (pessoa física ou jurídica) exposto às práticas abusivas, um banco comercial como fornecedor e a existência de produtos ou serviços bancários, temse uma relação jurídica de consumo, ocorrendo a plena aplicabilidade do Código de Defesa do Consumidor às operações bancárias, inclusive aos contratos de crédito, espécies do gênero contratos bancários.
O crédito possui papel fundamental na atual sociedade de consumo, pois é o fomentador das atividades empresariais e pessoais, e cada vez mais os agentes estão recorrendo às instituições bancárias para sua aquisição Os contratos de crédito bancário são do tipo adesão porque possuem cláusulas e condições gerais preestabelecidas unilateralmente pelos bancos (predisponente ou pólo ativo da relação contratual), em detrimento do mutuário-consumidor (aderente ou pólo passivo) sem que este possa discutir ou modificar substancialmente o conteúdo contratual.

Portanto, defende-se a ampla incidência do Código de Defesa do Consumidor às operações bancárias, em especial aos contratos de crédito, protegendo o consumidor (pessoa física ou jurídica) exposto às práticas abusivas cometidas pelos bancos nas relações jurídicas de consumo da sociedade moderna.

Assim, deve haver a adequação dos bancosfornecedores de produtos ou serviços à atual sistemática imposta pelo Código de Defesa do Consumidor, evitando abusividades e desequilíbrios na formulação e no cumprimento dos contratos, uma vez que o Direito tem um papel saneador e de pacificação social.

\section{Referências}

BRASIL. Código Comercial. Lei n ${ }^{\circ} 556$, de 25 de junho de 1850, colaboração de Antonio Luiz de Toledo Pinto e Márcia Cristina Vaz dos Santos Windt. 5.ed. São Paulo: Saraiva, 1999.

BRASIL. Código de Defesa do Consumidor. Lei no 8.078, de 11 de setembro de 1990. Dispõe sobre a proteção do consumidor e dá outras providências. Brasília, 1990.

BRASIL. Constituição [1988]. Constituição da República Federativa do Brasil. Brasília, 1988.

BRASIL. Novo Código Civil. Lei no 10.406, de 10 de janeiro de 2002: estudo comparativo com o código civil de 1916, São Paulo: Revista dos Tribunais, 2002.

CUNHA, Belinda Pereira. Antecipação da tutela no código de defesa do consumidor: tutela individual e coletiva, São Paulo: Saraiva, 1999. 
DELFINO, Lúcio. Consumidor brasileiro: amplitude de seu conceito jurídico. Revista Meio Jurídico, São José do Rio Preto, n.40, p.44-52, dez. 2000.

EFING, Antonio Carlos. Contratos e procedimentos bancários à luz do código de defesa do consumidor. São Paulo: Revista dos Tribunais, 1999.

GLITZ, Frederico Eduardo Zenedin. O código de defesa do consumidor e os contratos bancários. Jus Navigandi. Disponível em: <http://www1.jus.com.br/doutrina/ texto.asp?id=720> . Acesso em: 20 jul. 2001.
MANDELBAUM, Renata. Contratos de adesão $e$ contratos de consumo. São Paulo: Revista dos Tribunais, 1996.

NOVAIS, Alinne Arquette Leite. A teoria contratual e o Código de Defesa do Consumidor. São Paulo: Revista dos Tribunais, 2001.

POLASTRO, Marilene de Souza. Reflexões acerca do código de proteção e defesa do consumidor. 2000. Dissertação (Mestrado em Direito Negocial) - Universidade Estadual de Londrina, Londrina.

RIZZARDO, Arnaldo. Contratos de crédito bancário. 4. ed. São Paulo: Revista dos Tribunais, 1999. 